\title{
Effect of Ascorbic Acid on Antioxidant Defense Systems and Lipid Peroxidation in Guinea Pig
}

\author{
Ashwani Koul, Krishan L. KhandujA, ${ }^{*}$ Indu B. Koul, \\ Mahesh P. Gupta, Sabhiya MAJID, and \\ Rati Ram SHARMA
}

Department of Biophysics, Postgraduate Institute of Medical

Education and Research, Chandigarh-160012, India

(Received July 30, 1988)

\begin{abstract}
Summary In view of the antioxidant properties of ascorbic acid (AA), effects of inadequate and excessive doses of AA on hepatic and pulmonary antioxidant enzymes and NADPH-dependent lipid peroxidation were investigated in the present study. Male guinea pigs, dosed daily with $0.2 \mathrm{mg} \mathrm{AA} / 100 \mathrm{~g} \mathrm{~b}$ wt (inadequate) or $50 \mathrm{mg} \mathrm{AA} / 100 \mathrm{~g} \mathrm{~b}$ wt (excessive) for 8 weeks, demonstrated no difference in body growth, liver and lung weights, and post-10,000 $\times g$ supernatant protein contents as compared with the control group, which was daily fed with 2 mg AA/ $100 \mathrm{~g} \mathrm{~b}$ wt. Inadequacy of AA decreased the hepatic and pulmonary contents of catalase, glutathione peroxidase (GSH-Px), and superoxide dismutase (SOD), but it significantly increased glutathione reductase (GR) activity $(p<0.005)$ in lung. However, levels of hepatic and pulmonary NADPH-dependent lipid peroxidation remained unaltered when the supply of AA was inadequate. Excessive doses of AA did not influence any pulmonary antioxidant enzyme, level of NADPHdependent lipid peroxidation and content of reduced glutathione (GSH), but increased the hepatic GSH-Px and GR activities. Hepatic SOD activity showed a significant decrease $(p<0.01)$, whereas NADPHdependent lipid peroxidation and GSH contents remained unchanged. It appears that the changes in antioxidant enzymes may be a nonspecific response to AA or these changes may not be sufficient to bring about any shift in the levels of NADPH-dependent lipid peroxidation in the presence of unaltered GSH contents or other biomolecules which may act as antioxidants or free radical scavengers in the cell system.
\end{abstract}

Key Words: ascorbic acid, antioxidant enzymes, lipid peroxidation, guinea pig

\footnotetext{
*To whom all correspondence should be addressed.
} 
During the course of aerobic metabolic reactions a considerable amount of reactive oxygen species such as superoxide anions $\left(\mathrm{O}_{\dot{2}}^{\overline{2}}\right)$ and hydrogen peroxide $\left(\mathrm{H}_{2} \mathrm{O}_{2}\right)$ are generated [1-3]. $\mathrm{H}_{2} \mathrm{O}_{2}$ and $\mathrm{O}_{\dot{2}}^{-}$further undergo a variety of chain reactions and produce free radicals such as $\mathrm{OH}^{-}$and $\mathrm{HO}_{2}^{-}$. These radicals are capable of abstracting hydrogen atoms from polyunsaturated fatty acid and thereby initiate the process of lipid peroxidation $[4,5]$, which results in oxidative degradation and inactivation of various important biomolecules. A normal cell may control or prevent such adverse reactions with the help of nonenzymatic and enzymatic antioxidant defense systems. These include vitamin $\mathrm{E}$, which is capable of scavenging active oxygen species, such as, peroxyl radicals, superoxide anions and singlet oxygen. Superoxide dismutase (SOD) is the principal protective enzyme which dismutates $\mathrm{O}_{\overline{2}}^{-}$to $\mathrm{H}_{2} \mathrm{O}_{2}$ and $\mathrm{O}_{2}$ [6]. Hydrogen peroxide is detoxified by catalase and glutathione peroxidase (GSH-Px) [7, 8]. GSH-Px is further capable of reacting with lipid peroxides to control the process of peroxidation [9].

It has been suggested that ascorbic acid (AA) can also play the role of an antioxidant [10]; and a recent proposal has been made that ascorbate scavenges $\mathrm{OH}^{\prime}$, resulting in the formation of the ascorbate free radical (AFR), which is further converted into dehydroascorbic acid and ultimately to diketogulonic acid [11]. However the antioxidant properties of AA have not been clearly established experimentally in a well-controlled in vivo system. As a reducing compound, AA maintains sulfhydryl compounds including glutathione in a reduced state and participates in many redox reaction. It has also been shown that AA has a synergistic effect on the antioxidant functions of vitamin $\mathrm{E}$ and selenium $[12,13]$. In this study we present evidence that a large intake of AA failed to inhibit NADPH-dependent lipid peroxidation in guinea pigs. The effect of oral intake of different amounts of AA on antioxidant enzymes is also presented.

\section{MATERIALS AND METHODS}

Male weanling guinea pigs $(250-300 \mathrm{~g})$ of the institute colony were used in the experiments. All the animals were maintained on an AA- free stock diet plus water ad libitum. Animals were divided into three groups following a period of equilibration in chambers bedded with rice husk. AA dissolved in $1 \mathrm{ml}$ of freshly prepared $10 \%$ sucrose was administered orally by a blunt tip syringe. The control group received $2 \mathrm{mg} \mathrm{AA} / 100 \mathrm{~g} \mathrm{~b} w t /$ day, the inadequate AA group, $0.2 \mathrm{mg} \mathrm{AA} /$ $100 \mathrm{~g} \mathrm{~b} \mathrm{wt} /$ day, and the excessive AA group, $50 \mathrm{mg} \mathrm{AA} / 100 \mathrm{~g} \mathrm{~b} \mathrm{wt} /$ day. This treatment with AA was continued for 8 weeks. After this period, animals were sacrificed by exsanguination under light ether anaesthesia between 7-8 h. Thoracic and peritoneal cavities of the animals were opened and lung and liver were perfused immediately in situ with cold $0.15 \mathrm{M} \mathrm{KCl}$ containing $0.05 \mathrm{M}$ phosphate buffer, $\mathrm{pH}$ 7.4. Liver and lung were diced with scissors, homogenized with a Potter-Elvehjem homogenizer and diluted to a concentration of $1 \mathrm{~g}$ wet weight/4 $\mathrm{ml}$ with cold $0.05 \mathrm{M}$ phosphate buffer, $\mathrm{pH}$ 7.4. Homogenates were then centrifuged 
at $10,000 \times g$ for $20 \mathrm{~min}$ at $4^{\circ} \mathrm{C}$. The post- $10,000 \times g$ supernatant was used for the estimation of enzymatic activities of GSH-Px, catalase, SOD, and glutathione reductase (GR). GSH-Px was measured according to the method of Paglia and Valentine[14]. Catalase activity was determined by the method described by Luck [15]. SOD was measured according to Kono [16]. GR activity was measured following the method of Carlberg and Mannervik [17]. Reduced Glutathione (GSH) was estimated in the whole tissue homogenate by the method of Moron et al. [18]. NADPH-dependent lipid peroxidation was assayed by the method of Trush et al. [19] in lung and by that of Pederson et al. [20] in liver. With 20, 40, or $60 \mathrm{nmol}$ of AA in the reaction mixture, lipid peroxidation was also assayed in liver preparations of control animals.

Protein was determined by the method of Lowry et al. [21] using bovine serum albumin as standard.

Statistical significance of differences between groups was determined by unpaired Student's $t$-test.

\section{RESULTS}

Oral administration of excessive or inadequate doses of AA had no effect on body growth, organ weights, or post- $10,000 \times g$ supernatant protein contents. The influence of inadequate doses of AA on pulmonary antioxidant enzymes and on NADPH-dependent lipid peroxidation is depicted in Table 1. The activities of catalase, GSH-Px, and SOD decreased significantly. In contrast, AA deficiency increased GR activity, whereas the concentration of GSH increased nonsignificantly and levels of NADPH-dependent lipid peroxidation remained unaltered. In the case of liver, administration of inadequate doses of AA had effects similar to those in lung in all respects except for GR (Table 2) whose activity remained unaltered.

Influence of excessive doses of AA on lung antioxidant enzymes and NADPH-dependent lipid peroxidation is shown in Table 3. It was surprising to

Table 1. Effect of inadequate daily intake of ascorbic acid on pulmonary antioxidant defense system and lipid peroxidation in guinea pigs.

\begin{tabular}{lcc}
\hline Parameter & Control & Inadequate \\
\hline Catalase & $217 \pm 21.5$ & $140 \pm 10.4^{* *}$ \\
GSH-Px & $53.1 \pm 4.91$ & $38.9 \pm 3.18^{*}$ \\
GR & $20.5 \pm 1.36$ & $40.1 \pm 2.61^{* * *}$ \\
SOD & $5.15 \pm 0.32$ & $3.80 \pm 0.48^{*}$ \\
GSH & $1.63 \pm 0.13$ & $1.82 \pm 0.20$ \\
Lipid peroxides & $42.5 \pm 0.63$ & $41.9 \pm 1.67$ \\
\hline
\end{tabular}

Mean \pm SE $(n=5-6)$. Units are expressed as follows: Catalase, I.U/mg protein; GSH-Px and $\mathrm{GR}, \mathrm{nmol}$ of NADPH consumed/min/mg protein; SOD, units/mg protein; GSH, $\mu \mathrm{mol} / \mathrm{g}$ tissue; lipid peroxides, terms of nmol of malondialdehyde $/ \mathrm{g}$ tissue $/ 60 \mathrm{~min}$. $p$ values: ${ }^{*} p<0.05 ;{ }^{* *} p<0.01 ;{ }^{* * *} p<0.005$.

Vol. 6, No. 1, 1989 
Table 2. Effect of inadequate daily intake of ascorbic acid on hepatic antioxidant defense system and lipid peroxidation in guinea pigs.

\begin{tabular}{lcc}
\hline Parameter* & Control & Inadequate \\
\hline Catalase & $2,168 \pm 135$ & $1,366 \pm 112^{* * *}$ \\
GSH-Px & $264 \pm 6.70$ & $218 \pm 20.5^{*}$ \\
GR & $42.6 \pm 1.16$ & $35.8 \pm 4.20$ \\
SOD & $5.25 \pm 0.55$ & $3.27 \pm 0.31^{* *}$ \\
GSH & $9.18 \pm 0.97$ & $8.80 \pm 0.94$ \\
Lipid peroxides & $226 \pm 21.0$ & $214 \pm 25.5$ \\
\hline
\end{tabular}

Mean \pm SE $(n=5-6)$.

Units and significance are the same in Table 1, except for lipid peroxide level (in terms of nmol of malondiadehyde/g tissue/10 min).

Table 3. Effect of excessive daily intake of ascorbic acid on pulmonary antioxidant defense system and lipid peroxidation in guinea pigs.

\begin{tabular}{lcr}
\hline Parameter* & Control & Excessive \\
\hline Catalase & $204 \pm 15.8$ & $200 \pm 21.4$ \\
GSH-Px & $52.5 \pm 4.87$ & $55.3 \pm 3.90$ \\
GR & $21.2 \pm 2.37$ & $23.6 \pm 2.38$ \\
SOD & $5.24 \pm 0.53$ & $5.02 \pm 0.19$ \\
GSH & $1.59 \pm 0.13$ & $1.60 \pm 0.19$ \\
Lipid peroxides & $41.6 \pm 3.10$ & $41.3 \pm 3.21$ \\
\hline
\end{tabular}

Mean \pm SE $(n=5-6)$.

Units and significance are the same as in Table 1.

Table 4. Effect of excessive daily intake of ascorbic acid on hepatic antioxidant defense system and lipid peroxidation in guinea pigs.

\begin{tabular}{lcc}
\hline Parameter* & Control & Excessive \\
\hline Catalase & $2,168 \pm 201$ & $2,423 \pm 174$ \\
GSH-Px & $263 \pm 10.0$ & $358 \pm 7.45^{* * *}$ \\
GR & $41.6 \pm 2.68$ & $55.9 \pm 6.87^{*}$ \\
SOD & $4.95 \pm 0.27$ & $3.49 \pm 0.36^{* *}$ \\
GSH & $9.79 \pm 0.42$ & $9.42 \pm 0.17$ \\
Lipid peroxides & $238 \pm 14.8$ & $223 \pm 12.8$ \\
\hline
\end{tabular}

Mean \pm SE $(n=5-6)$.

Units and significance are the same as in Table 1, except for lipid peroxide level (in terms of nmol of malondialdehyde/g tissue/10 min).

find that AA was unable to induce any significant change in the NADPHdependent lipid peroxidation or antioxidant enzymes. As shown in Table 4, in liver of excessive AA fed guinea pigs, activities of GSH-Px and GR significantly increased. On the contray, SOD activity decreased $(p<0.01)$. All these changes, however, could not induce any change in the basal level of lipid peroxidation. Addition of AA at a level of 20,40 , or $60 \mathrm{nmol}$ in the reaction mixture $(1 \mathrm{ml})$ increased non-enzymatic lipid peroxidation, but NADPH-dependent lipid peroxidation still remained unaltered (data not included). 


\section{DISCUSSION}

SOD is known to be one of the key enzymatic defense fractors in the lung against a variety of toxic agents. Catalase and GSH-Px are also important, as they are responsible for the detoxification of peroxides. Our finding of decreased pulmonary and hepatic activities of SOD, GSH-Px, and catalase due to dietary deficiency of AA might have led to an increased formation of lipid peroxidation products because of impairment of the pathway of conversion of $\mathrm{O}_{2}^{-}$to $\mathrm{O}_{2}+\mathrm{H}_{2} \mathrm{O}_{2}$ and $\mathrm{H}_{2} \mathrm{O}_{2}$ to $\mathrm{H}_{2} \mathrm{O}+\mathrm{O}_{2}$. In turn, $\mathrm{H}_{2} \mathrm{O}_{2}$ and $\mathrm{O}_{2}^{-}$can undergo a variety of chain reactions to produce $\mathrm{HO}_{2}^{-}$and $\mathrm{OH}^{-}$radicals which initiate the process of lipid peroxidation. However, we could not detect any significant increase in the levels of NADPH-dependent lipid peroxidation in lung and liver in spite of impaired activities of the above mentioned enzyme. The nonsignificant $(p>0.05)$ increase in pulmonary GSH content in guinea pigs fed an inadequate amount of AA may be attributed to elevated $(p<0.005)$ activity of $\mathrm{GR}$, causing a changed redox state of GSH and GSSG.

Excessive intake of AA was also found to have no effect on NADPHdependent lipid peroxidation in lung and liver. Pulmonary antioxidant enzymes were not altered when the animals consumed excessive amounts of AA. However, in liver, the activity of SOD decreased and GSH-Px and GR activities increased in animals given excessive doses of AA. Addition of 20, 40, or $60 \mathrm{nmol}$ of AA to the reaction mixture of lipid peroxidation, which also did not result in any change in NADPH-dependent lipid peroxidation in liver coincides with our findings of no change in NADPH-dependent lipid peroxidation in liver of excessive AA-fed animals. Wartanowicz et al. [22] have also reported a nonsignificant decrease (8\%) in lipid peroxide levels in serum of elderly subjects after supplementation of 400 mg AA/day for 4 months.

The content of GSH, the principal non-protein sulfhydryl compound in tissues [23] as well as a cofactor for multiple glutathione-S-transferases and GSH-Px, was not altered in lung or liver due to inadequate or excessive intake of the vitamin. GSH is necessary for the stability of sulfhydryl containing enzymes and protects hemoglobin and many other cofactors from oxidation. The depletion of hepatic glutathione in vivo by phorone, vinylidene chloride, or diethyl maleate has been shown to enhance lipid peroxidation in vitro [24, 25], without affecting the GSH-Px activity. Thus GSH depletion appears to be one of the mechanisms which may cause peroxidative damage to the cellular membrane. From our results it looks as if the unchanged level of GSH was sufficient to maintain control over the levels of NADPH-dependent lipid peroxidation in spite of decreased activities of antioxidant enzyms in AA deficiency. It is also likely that a number of other enzymatic/nonenzymatic factors present in the cell may function as free radical scavengers or antioxidants under certain conditions. Therefore, under normal circumstances the metabolic machinery of the cell is capable of reversing any

Vol. 6, No. 1, 1989 
adverse effects of continuous oxidative stress in the cellular environment. Under conditions when the capacity of the cellular reducing power to reverse oxidative damage is decreased or when the oxidative stress is increased above the threshold, an irreversible injury to the cell may occur.

In conclusion, excessive intake or deficiency of AA did not cause any change in NADPH-dependent lipid peroxidation. The changes in antioxidant enzymes appear to be a nonspecific response or may not be sufficient to show a relationship between the enzymes and NADPH-dependent lipid peroxidation.

This work was financed by a research grant (IRIS ID NO. 8305240) from Indian Council of Medical Research, New Delhi, India.

\section{REFERENCES}

1. McCord, J.M., Keele, B.B., and Fridowich, I. (1971): An enzyme based theory of obligate anaerobiosis: The physiological function of superoxide dismutase. Proc. Natl. Acad. Sci. USA., 68, 1024-1027.

2. Gilette, J.R., Davis, D.C., and Sasame, H.A. (1972): Cytochrome P-450 and its role in drug metabolism. Annu. Rev. Pharmacol., 12, 57-84.

3. Paine, A.J. (1978): Excited states of oxygen in biology; their possible involvement in cytochrome P-450 linked oxidation as well as in the induction of P-450 system by many diverse compounds. Biochem. Pharmacol.; 28, 1805-1813.

4. Pryor, W.A. (ed.) (1976-1982): Free Radicals in Biology, Vol. I-V, Academic Press, New York.

5. Nygaard, O.F., and Simic, M.G. (eds.) (1983): Radioaprotectors and Anticarcinogens, Academic Press, New York.

6. Fridovich, I. (1975): Superoxide dismutase. Annu. Rev. Biochem., 44, 147-159.

7. Chrislophersen, B.O. (1968): Formation of monohydroxy polyenoic acids from lipid peroxides by glutathione peroxidase. Biochim. Biophys. Acta, 164, 35-46.

8. Comporti, M., Benedetti, A.S., and Chieli, E. (1973): Studies on in vitro peroxidation of liver lipids in ethanol-treated rats. Lipids, 8, 498-502.

9. Little, C., and O'Brien, P.J. (1968): An intracellular GSH-peroxidase with a lipid peroxide substrate. Biochem. Biophys. Res. Commun., 31, 145-150.

10. Seib, P.A., and Tolbert, B.M. (eds.) (1982): Ascorbic Acid: Chemistry, Metabolism and Uses, American Chemical Society, Washington, D.C.

11. Rose, R.C. (1987): Ascorbic acid protection against free radicals. Ann. NY. Acad. Sci., 498, 506-508.

12. Combs, G.F., Jr., and Scott, M.L. (1974): Antioxidant effects on sellenium and vitamin E function in the chick. J. Nutr., 104, 1297-1303.

13. Moran, E.T., Jr., Carlson, M.C., Bronan, R.G., Sweeney, P.R., George, J.C., and Stanley, D.W. (1975): Alleviating mortality associated with a vitamin E-selenium deficiency by dietary ascorbic acid. Poult. Sci., 54, 266-269.

14. Paglia, D.E., and Valentine, W.N. (1967): Studies on the quantitative and qualitative characterization of erythrocyte glutathione peroxidase. J. Lab. Clin. Med., 70, 158-169.

15. Luck, H. (1963): Methods of Enzymatic Analysis, Academic Press, New York, Section, 3, pp. $885-894$.

16. Kono, Y. (1978): Generation of superoxide radical during autooxidation of hydroxylamine and an assay for superoxide dismutase. Arch. Biochem. Biophys., 186, 189-195.

17. Carlberg, I., and Mannervik, B. (1975): Purification and characterization of the flavoenzyme glutathione reductase from rat liver. J. Biol. Chem., 250, 5475-5480.

18. Moron, M.S., Dipierre, J.W., and Mannervik, B. (1979): Levels of glutathione, glutathione 
reductase and glutathione S-transferase activities in rat lung and liver. Biochim. Biophys. Acta, 582, 67-78.

19. Trush, M.A., Mimnaugh, E.G., Ginsburg, E., and Gram, T.E. (1981): In vitro stimulation by paraquat of reactive oxygen-mediated lipid peroxidation in rat lung microsomes. Toxicol. Appl. Pharmacol., 60, 279-286.

20. Pederson, T.C., Buege, J.A., and -Aust, S.D. (1973): The role of reduced nicotinamide adenine dinucleotide phosphate-cytochrome C-reductase in liver microsomal lipid peroxidation. J. Biol. Chem., 248, 7134-7141.

21. Lowry, O.H., Rosebrough, N.J., Farr, A.N., and Rendall, R.J. (1951): Protein measurement with folin phenol reagent. J. Biol. Chem., 193, 265-275.

22. Wartanowicz, M., Panczenko-kresowska, B., Ziemlanski, S., Kowalska, M., and Okolska, G. (1984): The effect of $\alpha$-tocopherol and ascorbic acid on the serum lipid peroxide level in elderly people. Ann. Nutr. Metab., 28, 186-191.

23. Jocelyn, P.C. (1972): Biochemistry of the SH Group, Academic Press, New York, 247 pp.

24. Younes, M., and Siegers, C.P. (1980): Lipid peroxidation as a consequence of glutathione depletion in rat and mouse liver. Res. Commun. Chem. Pathol. Pharmacol., 27, 119-128.

25. Younes, M., and Siegers, C.P. (1981): Machanistic aspects of enhanced lipid peroxidation following glutathione depletion in vivo. Chem. Biol. Interact., 34, 257-266. 